\title{
Structural and Electrical Properties of Ni-Zn Ferrite Nanoparticles: Influence of Mixed Fuel Approach
}

\author{
V.R. Bhagwat ${ }^{1}$, M. N. Sarnaik ${ }^{2}$, V. D. Murumkar ${ }^{3}$, K. M. Jadhav ${ }^{4}$ \\ Department of Physics, Deogiri College Aurangabad (M.S.) India ${ }^{1}$ \\ Muktanand College, Gangapur, Aurangabad (M.S.) India ${ }^{2}$ \\ Department of Physics, Vivekanand College, Aurangabad (M.S.) India ${ }^{3}$ \\ Department of Physics, Dr. Babasaheb Ambedkar Marathwada University, Aurangabad, (M.S.) India ${ }^{4}$
}

\begin{abstract}
Ni}_{0.5} \mathrm{Zn}_{0.5} \mathrm{Fe}_{2} \mathrm{O}_{4}(\mathrm{Ni}-\mathrm{Zn})$ ferrite nanoparticles were synthesized by sol-gel auto combustion method using mixed fuel approach (citric acid and ethylene glycol) as a fuel. The metal nitrate to fuel ratio was taken as 1:(1:3). The as synthesized powder of Ni-Zn ferrite nanoparticles is annealed at $650 \mathrm{C}$ for $5 \mathrm{~h}$ and prepared sample was used for characterization and investigations of structural and electrical properties. The structural characterization of $\mathrm{Ni}-\mathrm{Zn}$ ferrite nanoparticles were done by X-ray diffraction technique. The average crystallite size obtained by Scherrer's formula is of the order of $21 \mathrm{~nm}$. The lattice constant determined from XRD data is in the reported range $8.3783 \AA$. The DC electrical resistivity was investigated from room temperature to $850 \mathrm{~K}$ using two probe techniques. DC electrical resistivity behaviour of $\mathrm{Ni}-\mathrm{Zn}$ ferrite nanoparticles suggests that the sample is semiconducting in nature.
\end{abstract}

Keywords: Ni-Zn ferrite; sol-gel auto combustion; XRD; citric acid and ethylene glycol.

\section{INTRODUCTION}

Ferrites are ferrimagnetic oxides consisting of ferric oxide and metal oxides. On the basis of crystal structure ferrites are grouped into three classes namely garnet, spinel and hexagonal ferrite. The spinel ferrites are widely studied because of their superior properties such as structural, magnetic, electrical and catalytic properties, all of which are different from those of their bulk counterparts and applications point of view in various and new fields like magnetic drug delivery, catalyst, sensors, biological, biomedical and medical science [1-4]. The spinel ferrite has the general formula of $\mathrm{M}-\mathrm{Fe} 2 \mathrm{O} 4$ where $\mathrm{M}$ is a divalent metal ion ( $\mathrm{Mn}, \mathrm{Co}, \mathrm{Ni}$, and $\mathrm{Zn}$ etc). Among spinel ferrites, $\mathrm{Ni}-\mathrm{Zn}$ ferrite $\left(\mathrm{CoFe}_{2} \mathrm{O}_{4}\right)$ has an inverse spinel structure and promising magnetic material for high-density recording applications because of their high magneto crystalline anisotropy, high coercivity, moderate saturation magnetization and high chemical and structural stability at higher temperatures, which make it a good candidate for the electronic components used in computers, recording devices, and magnetic cards [5-9].The properties of nanoparticles mostly depend on synthesis method therefore nowadays different synthesis methods are being used for synthesis nanomaterials. Ni-Zn ferrite nanoparticles have been synthesized using various methods, such as co-precipitation method, hydrothermal method, micro emulsion method, sol-gel method, sonochemical reaction method, ball milling, laser ablation and aerosol method [10-14]. Among synthesis methods, sol-gel auto combustion method has been used for synthesis of Ni-Zn ferrite nanoparticles. Auto-combustion synthesis process is based upon the thermo-chemical concept used in the field of propellants and explosives, its extrapolation to the combustion synthesis of nano-oxides. A various fuels have been used in the combustion synthesis of ferrite nonmaterial, like glycine, urea, oxalylhydrazine, citric acid, and sucrose. All these fuels serve two purposes: (i) they are the source of $\mathrm{C}$ and $\mathrm{H}$, the reducing elements, which form $\mathrm{CO}_{2}$ and $\mathrm{H}_{2} \mathrm{O}$ on combustion and liberate heat; and (ii) they form complexes with the metal ions facilitating homogeneous mixing of the cations in solution. The exothermicity of the redox reaction ranges from $1200 \mathrm{~K}$ to $1800 \mathrm{~K}$. The nature of combustion differs from flaming to non-flaming depending upon which fuel used for preparation of nanomaterial. In the present work new approach has been used to prepare Ni-Zn ferrite nanoparticles using mixed fuel (citric acid and ethylene glycol). To date very less work have been reported using mixture of citric acid and ethylene glycol.

The present research reports deals with the synthesize Ni$\mathrm{Zn}$ ferrite nanoparticles by sol-gel auto combustion method using mixture of citric acid and ethylene glycol as fuel and to investigate the structural and magnetic properties of $\mathrm{Ni}-\mathrm{Zn}$ ferrite nanoparticles. In the literature, structural and magnetic properties of $\mathrm{Ni}-\mathrm{Zn}$ ferrite nanoparticles are reported, but no systematic investigation of their electrical behaviour is reported. The electrical properties of spinel ferrite nanoparticles are important from the point of view of its use in transformer cores, humidity and gas sensor devices. 


\section{EXPERIMENTAL}

The Ni-Zn nanoparticles were synthesized by sol-gel autocombustion method using citric acid + ethylene glycol as a fuel. The metal nitrates to fuel ratio was taken as 1: (1:3) or (metal nitrate: (citric acid: ethylene glycol). All the reagents used for the synthesis of $\mathrm{Ni}-\mathrm{Zn}$ ferrite nanoparticles were analytical grade and used as received without further purification. The stoichiometric proportion of nickel nitrate $\mathrm{Ni}\left(\mathrm{NO}_{3}\right)_{2} 6 \mathrm{H}_{2} \mathrm{O}$, zinc nitrate $\mathrm{Zn}\left(\mathrm{NO}_{3}\right)_{2}$ $6 \mathrm{H}_{2} \mathrm{O}$,ferric nitrate $\mathrm{Fe}\left(\mathrm{NO}_{3}\right)_{3} \quad 9 \mathrm{H}_{2} \mathrm{O}$, citric acid $\mathrm{C}_{6} \mathrm{H}_{8} \mathrm{O}_{7} \cdot \mathrm{H}_{2} \mathrm{O}$ and ethylene glycol $\mathrm{C}_{2} \mathrm{H}_{6} \mathrm{O}_{12}$ were separately dissolved in minimum amount of distilled water using magnetic stirrer. After complete dissolution of metal nitrates in distilled water then $\mathrm{Ni}-\mathrm{Zn}$ nitrate and ferric nitrate solution were mixed and stirred sometime with constant heating at $90{ }^{\circ} \mathrm{C}$. After some stirring mixed citric acid + ethylene glycol solution was added to the nitrates solution. The all solution was again stirred for about $6 \mathrm{~h}$ at $90^{\circ}$ Con a hot plate with continuous stirring until it becomes viscous and finally formed a very viscous gel. The temperature is further raised up to $120^{\circ} \mathrm{C}$ so that the ignition of the gel suddenly starts. The dried gel was subsequently swelling into foam like and undergoes a strong self-propagating combustion reaction to give a lose $\mathrm{Ni}-\mathrm{Zn}$ ferrite nano-powder. Finally the as prepared lose $\mathrm{Ni}_{0.5} \mathrm{Zn}_{0.5} \mathrm{Fe}_{2} \mathrm{O}_{4}$ ferrite powder was grinded for $30 \mathrm{~min}$ and annealed at $650^{\circ} \mathrm{C}$ temperature for $5 \mathrm{~h}$ in muffle furnace to improve the ordering and for further characterization.

\section{Characterizations}

The crystalline phase of the prepared $\mathrm{Ni}_{0.5} \mathrm{Zn}_{0.5} \mathrm{Fe}_{2} \mathrm{O}_{4}$ ferrite sample was identified by $\mathrm{X}$-ray diffraction technique using XPERT-PRO system. X-ray powder diffractions were performed at room temperature using monochromatic $\mathrm{Cu}-\mathrm{K}_{\alpha}$ radiation with $\lambda=1.54060 \quad \AA$ operated at $40 \mathrm{kV}$ and $35 \mathrm{~mA}$ with $2 \theta$ ranging from $20^{\circ}$ to $80^{\circ}$ at a step size $0.02^{\circ}$ per second. DC electrical resistivity was measured by two probe method. A small constant voltage was applied across the sample and the current through the sample was measured with respect to temperature. Temperature of the sample in the form of pellet was measured with chromel-alumel thermocouple.

\section{RESULTS AND DISCUSSIONS}

Fig. 1 shows the XRD pattern of the annealed $\mathrm{Ni}_{0.5} \mathrm{Zn}_{0.5} \mathrm{Fe}_{2} \mathrm{O}_{4}$ ferrite nanoparticles. The diffraction peaks observed at $2 \theta=30.32^{\circ}, 35.65^{\circ}, 43.33^{\circ}, 53.67^{\circ}, 57.24^{\circ}$, $62.80^{\circ}$ corresponding to the (220), (311), (400), (422), (511) and (440) planes, respectively. In this XRD pattern other oxides or impurity phases are not detected therefore XRD patterns confirm the formation of cubic spinel type lattice of $\mathrm{CoFe}_{2} \mathrm{O}_{4}$, which matches well with the standard XRD pattern (JCPDS No: 22-1086). The lattice constant (a) of Ni-Zn ferrite samples was obtained from the following equation.

$$
\mathrm{a}=\mathrm{d} \sqrt{ }\left(\mathrm{h}^{2}+\mathrm{k}^{2}+\mathrm{l}^{2}\right) \quad \AA \quad(1)
$$

where, (h k l) are the Miller Indices, $\mathrm{d}$ is inter planner spacing. Thus, lattice constant was computed using the $d$ value and the ( $\mathrm{h} \mathrm{k}$ l) parameters.

The crystallite size (D) has been calculated from FWHM (full width at half maximum) of most intense peak (311) data using Debye-Scherrer's equation [15].

$$
\mathrm{D}=\frac{(0.9 \lambda)}{(\beta \cos \theta)} \quad \mathrm{nm}
$$

where, $\mathrm{D}$ is the crystallite size, $\lambda$ is the wavelength of $\mathrm{Cu}$ $\mathrm{K}_{\alpha}(1.5405 \AA), \beta$ is the full width at half maxima of the most intense diffraction peaks and $\theta$ is the Bragg's angle. The reflection from (311) plane was used for determination of average crystallite size.

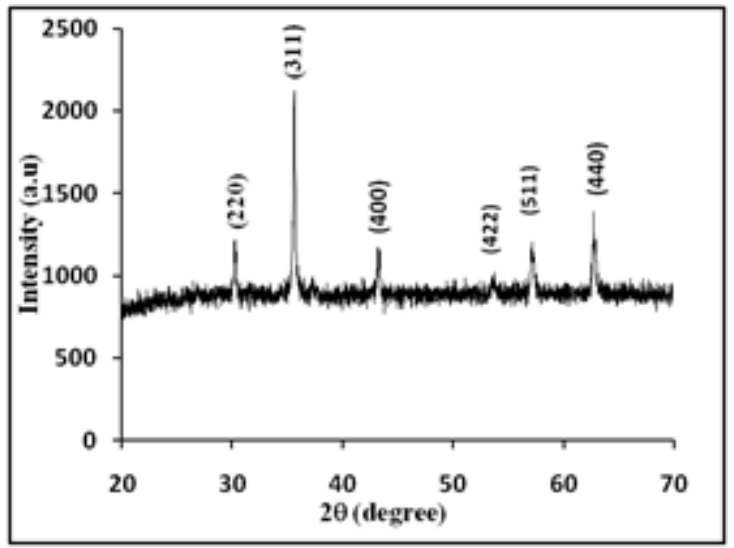

Fig. 1. XRD pattern of Ni-Zn ferrite nanoparticles

The unit cell volume $(\mathrm{V})$ was calculated by using the following equation;

$$
\mathrm{V}=\mathrm{a}^{3} \quad[\mathrm{~A}]
$$

where, V is the volume of unit cell, ' $a$ ' is the lattice constant.

The X-ray density $\left(\rho_{\mathrm{b}}\right)$ of the sample was calculated using the relation [16].

$$
\rho_{\mathrm{b}}=\frac{8 \mathrm{M}}{\mathrm{N}_{\mathrm{A}} \mathrm{a}^{3}} \mathrm{gm} / \mathrm{cm}^{3}
$$

Where, $M$ is the molecular weight and $N_{A}$ is the Avogadro's number and ' $a$ ' is the lattice parameter. As there are 8 molecules in the unit cell, so 8 is included in the formula. The bulk density $\left(\rho_{\mathrm{m}}\right)$ of Ni-Zn ferrite sample was determined using standard formula.

$$
\rho_{\mathrm{m}}=\frac{\mathrm{m}}{\pi \mathrm{r}^{2} \mathrm{t}} \mathrm{gm} / \mathrm{cm}^{3}
$$

Where, $\mathrm{m}$ is mass of pellets, $\mathrm{r}$ is the radius of pellets and $\mathrm{t}$ is thickness of pellet.

The structural parameters such as lattice constant, unit cell volume, X-ray density, bulk density and specific surface area of Ni-Zn ferrite nanoparticles are given in Table 1. From table 1, it was understood that the calculated values of lattice constant of Ni-Zn ferrite nanoparticles is 8.378 $\mathrm{A}^{\mathrm{o}}$ which agree with the reported values [17].The crystallite size of the Ni-Zn ferrite nanoparticles is $16 \mathrm{~nm}$. Small crystallite size is due to using mixed. The X-ray density is found to be of the order of $5.301 \mathrm{gm} / \mathrm{cm}^{3}$. The 
bulk density of Ni-Zn ferrite nanoparticles was measured from the standard formula [18].

TABLE I Lattice constant, volume of unit cell, X-ray density, bulk density and average crystallite size from XRD data

\begin{tabular}{|l|l|}
\hline Structural Parameters & Values \\
\hline Lattice constant $(\mathrm{a})$ & $8.379 \AA$ \\
\hline Volume of unit cell $(\mathrm{V})$ & $588.0 \AA^{3}$ \\
\hline X-Ray density $\left(\rho_{\mathrm{x}}\right)$ & $5.302 \mathrm{~g} / \mathrm{cm}^{3}$ \\
\hline Bulk density $\left(\rho_{\mathrm{b}}\right)$ & $2.749 \mathrm{~g} / \mathrm{cm}^{3}$ \\
\hline Crystallite size $(\mathrm{t})$ & $21.23 \mathrm{~nm}$ \\
\hline
\end{tabular}

The value of bulk density is of the order of $2.749 \mathrm{gm} / \mathrm{cm}^{3}$. It was observed that X-ray density of sample is greater than its bulk density. This was due to the pores present in the prepared materials. The increase in porosity is due to preparation condition [19].All the structural data of prepared $\mathrm{Ni}-\mathrm{Zn}$ ferrite nanoparticles is in the reported range.

\section{Electrical Properties}

The electrical behavior of Ni-Zn ferrite nanoparticles was studied by measuring dc resistivity as a function of temperature using two probe techniques. Temperature variation of dc resistivity is shown in Fig. 2 It is evident from Fig. 2 that the plot of $\log \rho$ versus 1000/T exhibit the similar nature to that of bulk Ni-Zn ferrite. It can be further observed from Fig.2 that resistivity decreases with increase in temperature indicating the semiconducting nature of the samples and obeys the Arrhenius relation [20];

$$
\rho=\rho_{\mathrm{o}} \mathrm{e}^{(\Delta \mathrm{E} / \mathrm{KT})}
$$

where, $\rho_{0}$ is resistivity at room temperature, $\mathrm{k}$ is the Boltzmann constant, $\Delta \mathrm{E}$ is the activation energy and $\mathrm{T}$ is the absolute temperature.

The resistivity plot shows two regions high temperature region (ferrimagnetic) and low temperature region (paramagnetic) separated at a particular temperature which may correspond to Curie temperature of Ni-Zn ferrite. A change in slope is contributed to change in conduction mechanism or phase transition from ferrimagnetic to paramagnetic. The conduction mechanism can be explained on the basis of Verwey model [21].

According to Verwey, the conduction mechanism in ferrite occurs mainly due to hopping of $\mathrm{Fe}^{2+}$ and $\mathrm{Fe}^{3+}$ ions in the octahedral [B] site. It is well known that hopping probability depends upon the separation between ions and the activation energy. The activation energy can be determined from slope of the linear plots of dc electrical resistivity (Fig. 2) and the Arrhenius relation [Eq.8]. The calculated value of activation energy is of the order of $0.397 \mathrm{eV}$. The activation energy of material is associated with mobility of charge carrier. The charge carriers are located with ions or vacant site and conduction takes place through hopping process.

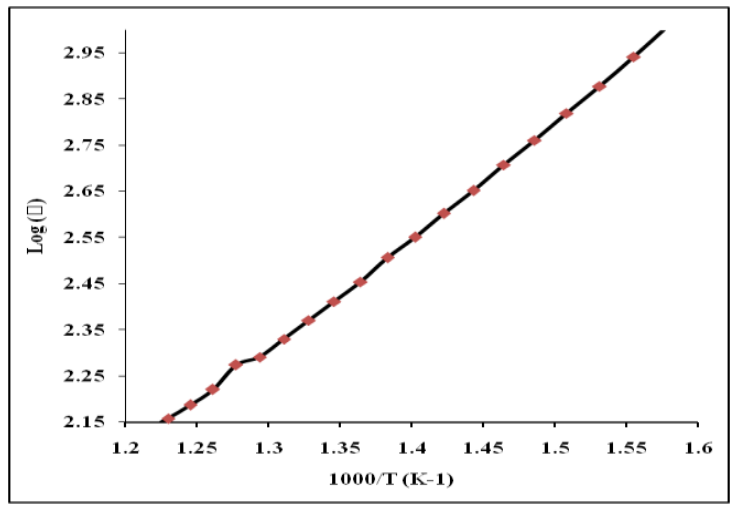

Fig.2. Temperature dependence of $\mathrm{d}$ c resistivity of $\mathrm{Ni}-\mathrm{Zn}$ ferrite nanoparticles

\section{IV.CONCLUSION}

$\mathrm{Ni}_{0.5} \mathrm{Zn}_{0.5} \mathrm{Fe}_{2} \mathrm{O}_{4}$ ferrite nanoparticles have been synthesized successfully by sol-gel auto combustion method using mixed fuel. X-ray diffraction pattern confirms the formation of cubic spinel structure in single phase without any impurity peak. The average crystallite size is obtained was of the order $21 \mathrm{~nm}$. The lattice constant and other structural parameter are in the reported range. The D.C. electrical resistivity decreases with increase in temperature obeying Arrhenius plot. The activation energy calculated from D.C electrical resistivity versus temperature is of the order of $0.397 \mathrm{eV}$.

\section{REFERENCES}

[1] V. J. Sawant, S. R. Bamane, Int. J. Pharm. Sci. Rev. Res. 20 (2013) 159.

[2] M. Kooti, M. Afshari ,ScientiaIranica. 19 (2012) 1991.

[3] J. A. Paulsen, A. P. Ring, and C. C. H. L, J. of Applied Physics 97 (2005) 044502

[4] O. Caltun, G.S.N. Rao, K.H. Rao.J. of Magn. and Magnetic Materials00 (2006)

[5] S. Amiri, S. shokrollahi. Material Science and Engineering C 33(1) (2013)1.

[6] M. H. Sousa, F. A. Tourinho, J. Depeyrot, G. J. da Silva, and M. C. F. L. Lara, J. Physical Chem. B. 105 (2001) 1168

[7] Z. Chen and L. Gao, Mater. Sci. and Eng: B.141 (2007) 82

[8] A. P. Alivisatos, Science. 271 (1996) 933.

[9] M. Sugimoto, J. of the Amer. Ceramic Society. 82 (1999) 269.

[10] Yue Zhang, Zhi Yang, Di Yin,Yong Liu, J. Magn. and Magnetic Materials 322 (2010) 3470

[11] A. Cabañas and M. Poliakoff, J. Mater. Chem., 11 (2001) 1408

[12] Y. Ahn, E. J. Choi, S. Kim, and H. N. Ok. Mater Letters 50 (2001) 47.

[13] J.-G. Lee, J. Y. Park, and C. S. Kim, J. Mater. Science 33 (1998) 3965.

[14] K. V. P. M. Shafi, A. Gedanken, R. Prozorov and J. Balogh, Chem. of Materials , 10 (1998) 103445

[15] B.D.Cullity, Elements of X-Ray Diffraction, Second ed., AddisonWesley. (1967).284.

[16] Khirade, P. P., Birajdar, S. D., Humbe, A. V., \& Jadhav, K. M. (2016), Journal of Electronic Materials, 45(6), 3227-3235.

[17] M. George, S.S. Nair, A.M. John, P. A. Joy, J. Phys. D: Appl. Phys. 39 (2006) 900.

[18] S. P. Yadav, S. S. Shinde, A. A. Kadam, and K. Y. Rajpure. Journal of Semiconductors. 34 (2013) 093002

[19] Sagar E. Shirsath, B.G. Toksha and K.M. Jadhav. Mat. Chem. Phys. 117 (2009) 163.

[20] Khirade, P. P., Birajdar, S. D., Raut, A. V., \& Jadhav, K. M. (2016), Journal of Electroceramics, 37(1-4), 110-120.

[21] R. D Waldron, Physical review. 99 (1955) 1727. 